\title{
Creep behaviour and life assessment of a cast nickel - base superalloy MAR - M247
}

https://doi.org/10.1515/htmp-2019-0006

Received Aug 01, 2018; accepted Nov 08, 2018

\begin{abstract}
The cast nickel-base MAR-M247 superalloy has been widely used for high-temperature components. In this work, the creep behaviour of two alternates of MARM247 superalloy with different grain size processed at different temperatures of casting are compared. Under the creep testing conditions used in this study, only negligible differences of creep behaviour of the alternate alloys were found and the evaluated creep characteristics correspond to the power-law or dislocation creep. The microstructure of the alloys consists of a $\gamma$ matrix with a eutectic, $\gamma^{\prime}$ strengthening cubic precipitates, and $\mathrm{M}_{6} \mathrm{C}$ and $\mathrm{M}_{23} \mathrm{C}_{6}$ carbides. Increasing the temperature induces the dissolution of some $\mathrm{M}_{23} \mathrm{C}_{6}$ carbides. Fractures of both variants of alloys exhibit a more ductile character at higher temperatures, while at lower temperature a mixture of brittle and ductile fracture modes was observed, which changes the creep fracture ductility.
\end{abstract}

Keywords: Creep, MAR-M247 superalloy, deformation mechanisms, life assessment

PACS: $81.05 . \mathrm{Bx}$

\section{Introduction}

The cast nickel-base polycrystalline superalloy MARM247 exhibits excellent resistance against high thermo-

\footnotetext{
*Corresponding Author: Marie Kvapilova: Institute of Physics of Materials, Academy of Sciences of the Czech Republic, CZ - 61662 Brno, Czech Republic; CEITEC IPM, Institute of Physics of Materials, Academy of Sciences of the Czech Republic, CZ - 61662 Brno, Czech Republic; Email: kvapilova@ipm.cz

Jiri Dvorak, Petr Kral, Vaclav Sklenicka: Institute of Physics of Materials, Academy of Sciences of the Czech Republic, CZ - 61662 Brno, Czech Republic; CEITEC IPM, Institute of Physics of Materials, Academy of Sciences of the Czech Republic, CZ - 61662 Brno, Czech Republic

Karel Hrbacek: Institute of Physics of Materials, Academy of Sciences of the Czech Republic, CZ - 61662 Brno, Czech Republic
} ๖ Open Access. ( 2019 M. Kvapilova et al., published by De Gruyter. (cc) BY 4.0 License mechanics loading and has been widely used for high- temperature components, such as advanced turbine blades and rotating parts in the aerospace industry, power generation equipment and gas turbine engines. The balanced composition of superalloy MAR-M247 provides a great combination of good castability and mechanical properties such as strength, superior creep properties and hot corrosion resistance at elevated temperatures. These excellent mechanical properties result from the presence of the gamma-prime precipitate strengthening that is enhanced by solid solution and grain boundary strengthening [1-3]. A refinement microstructure process, where fine primary carbides and gamma-prime precipitates in the gamma matrix can improve the mechanical properties, is a process that can be used for the improving the lifetime and reliability of superalloys [4]. However, the fine-grained superalloy MAR-M247 can exhibit lower ductility and a poor strength due to casting microporosity [5].

Currently, there are very limited published reports on the creep behaviour and the basics of the creep mechanism(s) acting in this superalloy. The controlling creep mechanism was suggested as dislocation climb and glide, based only on creep tests carried out under constant load at one temperature $\left(871^{\circ} \mathrm{C}\right)$ and following microstructure observation of creep specimen [6]. Such an idea is further supported by creep deformation map for related superalloy MAR-M200 [7]. Therefore, the aim of this study is to describe the creep behaviour and the operating creep deformation mechanism(s) in the MAR-M247 superalloy at wide range of elevated temperatures and applied stresses. A further aim is to compare the creep behaviour of two variants of this alloy processed by different casting temperatures. The casting temperature can influence the grain size and consequently mechanical properties of the alloy. The very important aspect of this study is a reliable creep life assessment of MAR-M247 superalloy. 


\section{Alloy compositions and experimental methods}

\subsection{Alloy}

The MAR-M247 superalloy was provided by PBS Velká Bíteš, a.s., Czech Republic, in the form of pre-cast rods. The chemical composition of the alloy was the following (in wt.\%): $0.15 \mathrm{C}, 8.37 \mathrm{Cr}, 0.67 \mathrm{Mo}, 5.42 \mathrm{Al}, 1.01 \mathrm{Ti}, 3.05 \mathrm{Ta}$, 9.92 W, $9.91 \mathrm{Co}, 0.04 \mathrm{Nb}, 0.015 \mathrm{Br}, 1.37 \mathrm{Hf}$, bal. Ni. For the study, two alternates of the alloy have been used, namely alloy $\mathrm{G}$ and $\mathrm{G} 1$. The preheating temperature of the casting mold was $1390^{\circ} \mathrm{C}$ for both alternates. The temperature during the pouring into the mold was $1300^{\circ} \mathrm{C}$ for alloy $\mathrm{G}$ and $1060^{\circ} \mathrm{C}$ for alloy G1. The lower temperature was predicted to induce a smaller grain size in the microstructure of alloy G1. Both variants underwent a hot isostatic pressing (HIP) procedure $\left(1200^{\circ} \mathrm{C} / 4 \mathrm{~h}, 100 \mathrm{MPa}\right)$. The alloys were subsequently heat treated by two steps. First, the solution annealing at $1200^{\circ} \mathrm{C}$ for 2 hours was carried out, second precipitation annealing at $870^{\circ} \mathrm{C}$ for 24 hours was performed. The grain size was determined by using the mean linear intercept length for grains on optical micrographs; grain size values were $5 \mathrm{~mm}$ and $2 \mathrm{~mm}$ for alloys $\mathrm{G}$ and G1, respectively.

\subsection{Experimental methods}

Standard constant load uniaxial tensile creep tests were carried out at the applied stress ranging from 150 to 700 $\mathrm{MPa}$ and at the testing temperatures 800, 900, 950 and $1000^{\circ} \mathrm{C}$. The creep elongations were measured using a linear variable differential transducer and were continuously recorded digitally and computer processed. All creep tests were run to the final fracture of the specimen. Cylindrical creep specimens with a gauge of $50 \mathrm{~mm}$ in length and 3.5 $\mathrm{mm}$ in diameter were used in this study.

The specimens for microscopy analysis were prepared by polishing and etching (etching solution $10 \mathrm{ml} \mathrm{HNO}_{3}$ $+5 \mathrm{ml} \mathrm{HCl}$ ). The fracture surfaces and longitudinal crosssections of the specimens were observed by scanning electron microscopy (SEM) (LYRA, Tescan).

\section{Results}

\subsection{Creep behaviour}

The description of creep behaviour and the evaluation of the main creep characteristics as the minimum creep rate and time to fracture were made from standard creep curves. Representative creep curves for superalloy MAR-M247 variant $\mathrm{G}$, describing the time dependence of creep strain were obtained at temperature of $800,900,950$ and $1000^{\circ} \mathrm{C}$, and at different applied stresses. They are shown in Figures 1ad. As expected for a given temperature, the time to fracture became shorter at higher applied stresses. The values of fracture elongations are ranging between about $3 \%$ and $8 \%$.

\subsection{Microstructure}

The microstructure of both as-received states of the alloys $\mathrm{G}$ and G1 consisted of coarse dendritic grains with carbides and a eutectic. Gamma prime strengthening cubic precipitates were dispersed in the gamma matrix. The microstructures of as-received MAR-M247 G and G1 are shown in Figures $2 \mathrm{a}$ and $2 \mathrm{~b}$. In the small part of Figure 2a, the cubic gamma prime structure is illustrated in more detail, whereas the small part of Figure $2 \mathrm{~b}$ shows $\mathrm{M}_{23} \mathrm{C}_{6}$ carbides and eutectics in the MAR-M247 microstructure. The microstructure of analyzed MAR-M247 superalloy exhibited about 60 vol. $\%$ of the gamma prime particles in the gamma matrix. Alloying by Mo, Co, Ti, W and other additives leads to further solid solution and precipitation strengthening of the matrix, and thus to an increased strengthening effect in the gamma phase. Especially, the addition of element Ta (characterized by its high melting point) can curb the coagulation and growth of the $\gamma^{\prime}$ phase [8]. Furthermore, creep behaviour could be influenced by carbides of the type $\mathrm{M}_{23} \mathrm{C}_{6}$, $\mathrm{MC}$ and $\mathrm{M}_{6} \mathrm{C}$ [9]. However, it was observed that these carbides are not stable. The carbides may undergo changes to their size and morphology due to operating temperature and applied stress. These changes could influence the creep properties of the alloys during longterm high-temperature exposure.

It should be noted that a rather coarse grain of both experimental materials $(5 \mathrm{~mm}$ for the $\mathrm{G}$ alloy and $2 \mathrm{~mm}$ for the G1 alloy) could influence the creep behavior and increase scatter in the results, particularly for creep life and rupture ductility. However, no coarsening of grain size was observed during the creep exposures of both superalloys. 

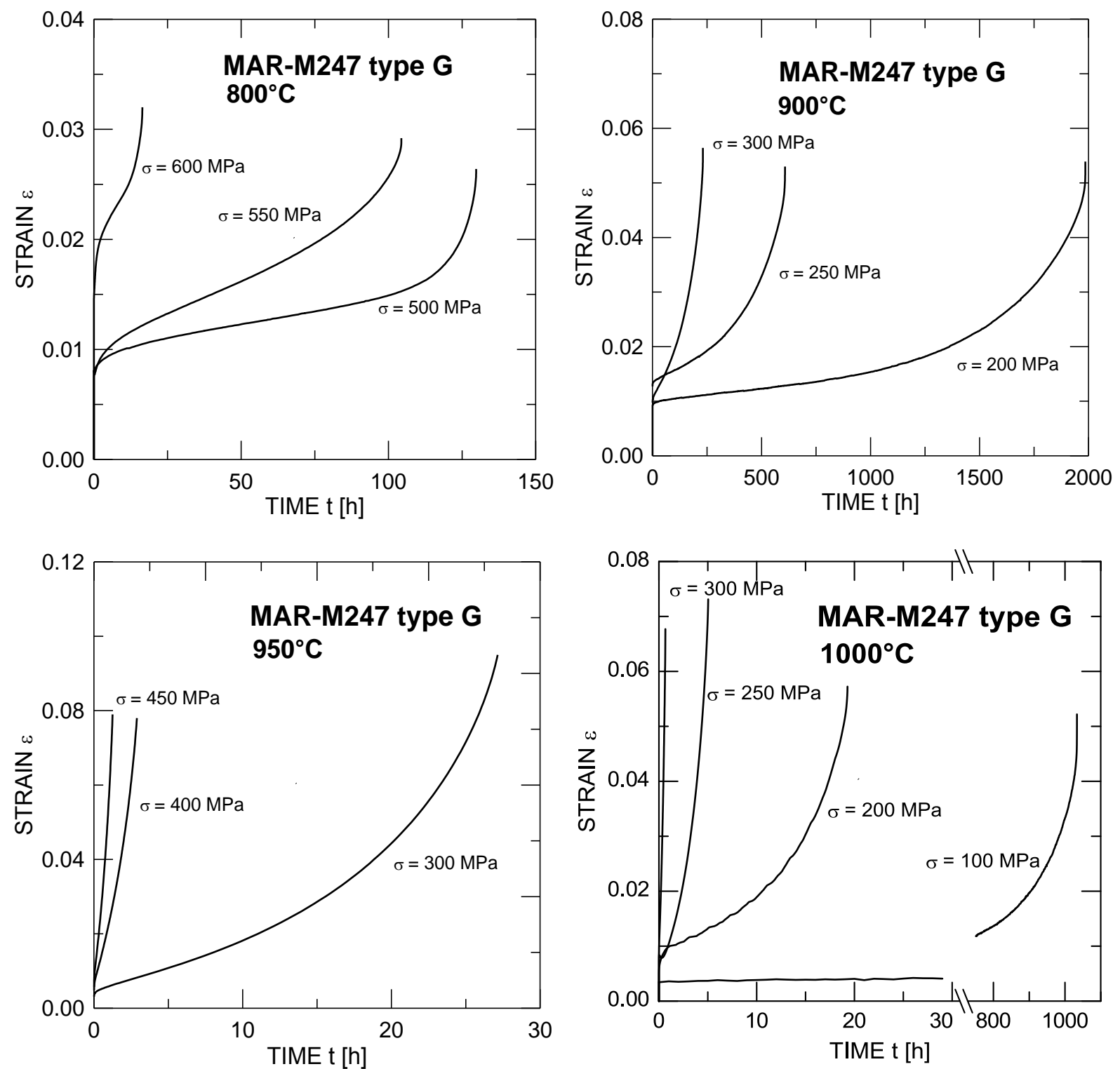

Figure 1: Representative creep curves for the superalloy MAR-M247 alloy G - the time dependence of creep strain obtained at temperatures ranging $800-1000{ }^{\circ} \mathrm{C}$ at different levels of applied stresses.

The microstructure of $\mathrm{G}$ and $\mathrm{G} 1$ alloys crept under two different creep temperatures $800^{\circ} \mathrm{C}$ and $950^{\circ} \mathrm{C}$ at the applied stress $400 \mathrm{MPa}$ are shown in Figures 3-6 under various magnifications. The microstructures consist of dendrites with carbides and gamma prime phase cubic precipitates dispersed in the matrix. The carbides are probably $\mathrm{M}_{23} \mathrm{C}_{6}$ type and/or $\mathrm{M}_{6} \mathrm{C}$ type, which were observed using their diffraction patterns taken by TEM $[10,11]$. The $\mathrm{M}_{6} \mathrm{C}$ type is more stable at high temperatures than $\mathrm{M}_{23} \mathrm{C}_{6}$ and therefore is more beneficial to the mechanical properties of the alloy. The gamma prime precipitates were observed in dual size modification: the primary $\gamma^{\prime}$ has an average size of $2 \mu \mathrm{m}$ and the secondary $\gamma^{\prime}$ has an average size of
$0,5 \mu \mathrm{m}$. Both of them can effectively hinder the dislocation slip to enhance the creep-rupture life. Based on the microstructure observation in [7], the best creep strength and ductility can be achieved, when the size of $\gamma^{\prime}$ ranges from 0.1 to $0.5 \mu \mathrm{m}$. When the size of $\gamma^{\prime}$ is extremely small, the dislocations can easily cut or bypass these small particles. On the other hand, when the size of $\gamma^{\prime}$ is large, the dislocation could be accumulated in the interface of $\gamma^{\prime}$ and $\gamma$, where cracks can nucleate. The needle-like precipitates (Figure 4a) could be according to their shape the TCP (topologically closed packed phase), observed and identified in [6] using their EDS spectra and selected-area diffraction 

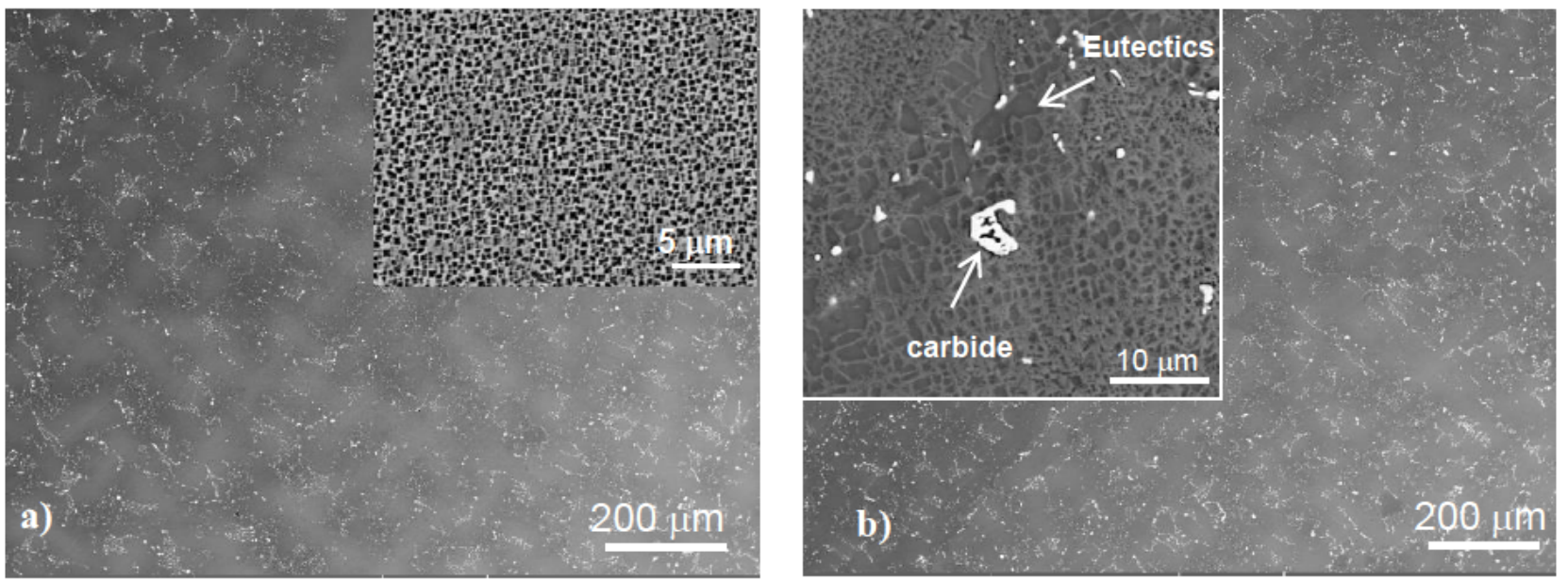

Figure 2: Microstructure of as-received state of (a) G alloy, and (b) G1 alloy.
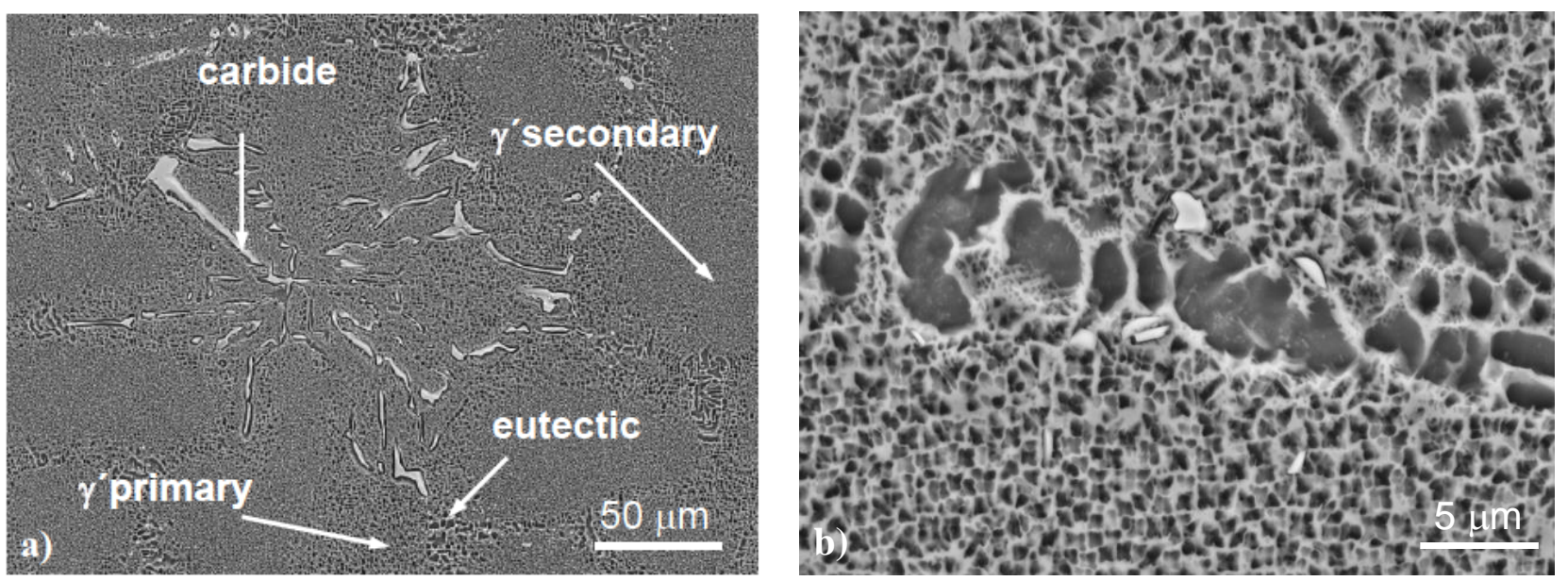

Figure 3: Microstructure of alloy $\mathrm{G}$ crept at $800^{\circ} \mathrm{C}$ and $400 \mathrm{MPa}$ at different magnification.
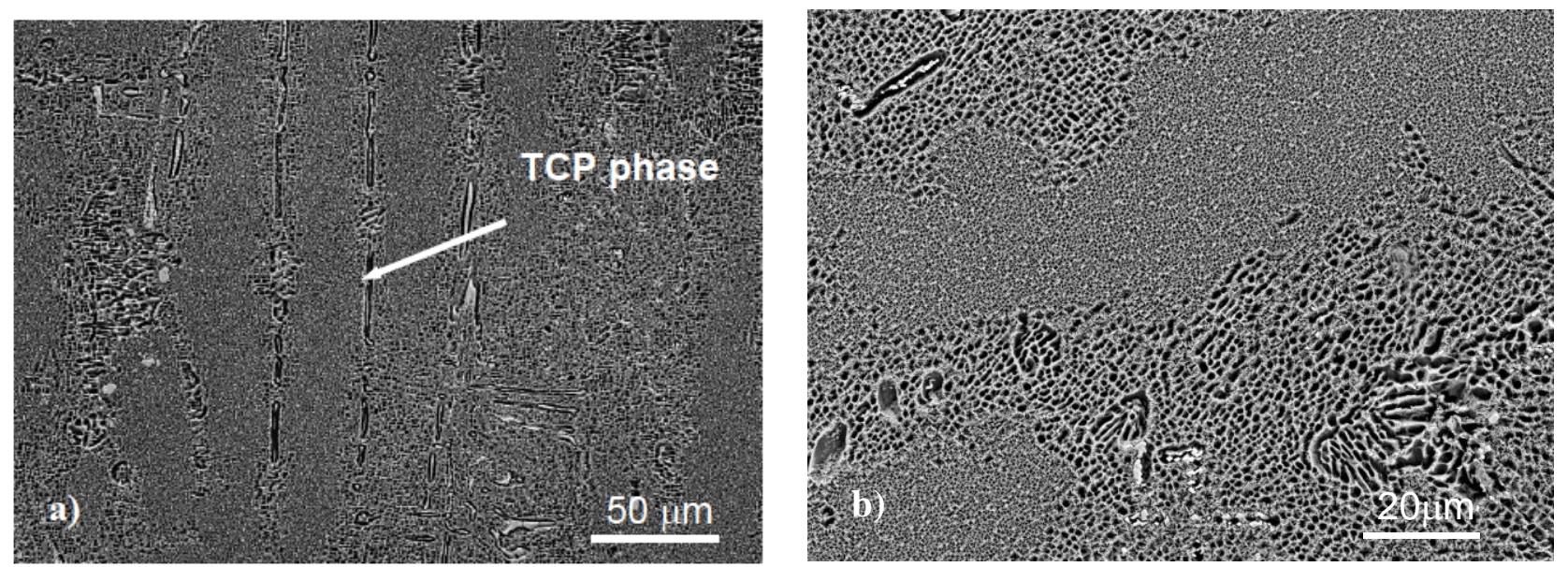

Figure 4: Microstructure of alloy $\mathrm{G}$ crept at $950^{\circ} \mathrm{C}$ and $400 \mathrm{MPa}$ at different magnification. 

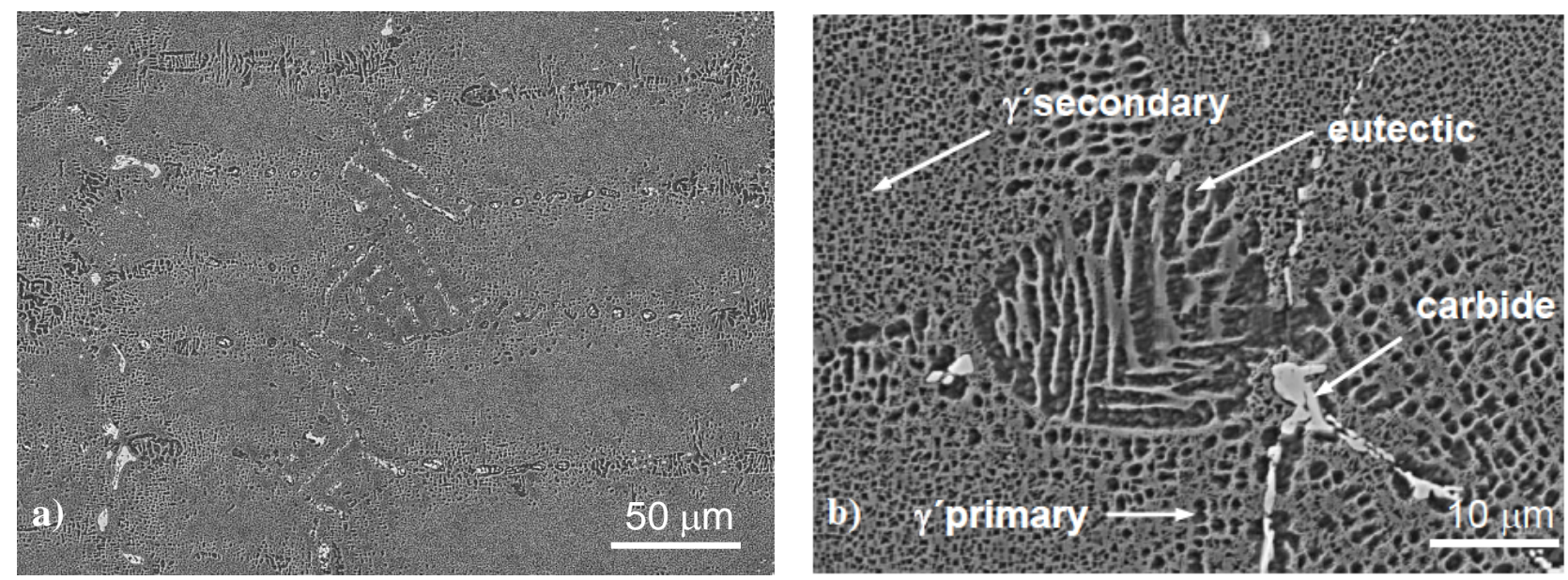

Figure 5: Microstructure of alloy $\mathrm{G} 1 \mathrm{crept}$ at $800^{\circ} \mathrm{C}$ and $400 \mathrm{MPa}$ at different magnification.
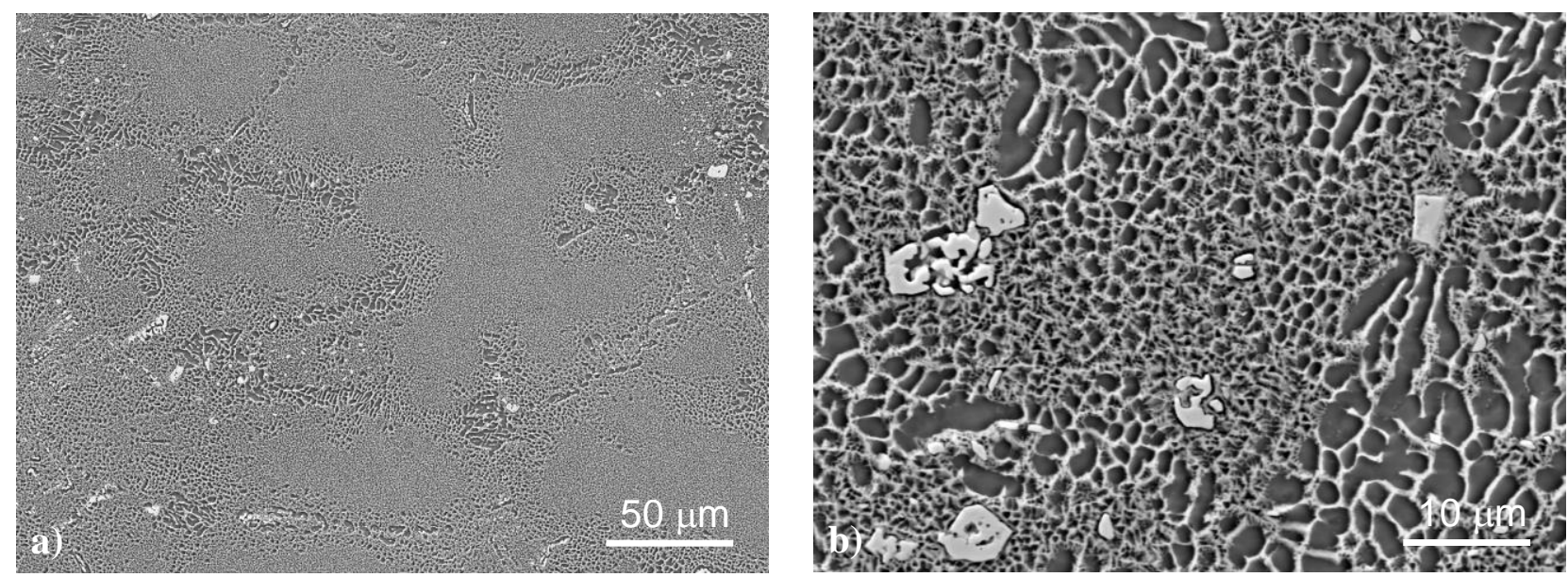

Figure 6: Microstructure of alloy $\mathrm{G} 1$ crept at $950^{\circ} \mathrm{C}$ and $400 \mathrm{MPa}$ at different magnification.

pattern, which has a deleterious effect on creep ductility as a place for creep damage nucleation.

According to EDX analysis of observed carbides $\mathrm{M}_{6} \mathrm{C}$ or $\mathrm{M}_{23} \mathrm{C}_{6}$ type, the $\mathrm{M}$ is mostly $\mathrm{Cr}$, Ti, Ta and $\mathrm{Hf}$ and had partially dissolved at the elevated temperature. The dissolution of certain volume of carbides can be explained by the lower thermal stability of $\mathrm{M}_{23} \mathrm{C}_{6}$ type carbides compared to $\mathrm{M}_{6} \mathrm{C}$ at elevated temperatures.

\subsection{Fracture behaviour of superalloys MAR-M247}

SEM images of fracture surfaces of tensile tested creep specimens of both variants of alloys MAR-M247 are presented in Figures 7 and 8. Observations indicate that fracture surfaces exhibit a more ductile character at higher temperatures. However, at a lower temperature, a mixture of brittle and ductile fracture mode was observed. The different types of fracture are in good agreement with the increase of creep ductility detected for alloys crept under higher temperatures (Table 1). This should be caused by the changing of sizes of the $\gamma^{\prime}$ phase, and $\mathrm{M}_{6} \mathrm{C}$ and $\mathrm{M}_{23} \mathrm{C}_{6}$ type of carbides over the time: these size changes include coarsening and/or dissolution.

\section{Discussion}

Creep data obtained from creep curves and Table 1 for the $G$ variant are depicted in Figures 9a and 9b. In Figure 9a, the minimum creep rates $\dot{\varepsilon}_{\text {min }}$ are plotted against the applied stress $\sigma$ on a bilogarithmic scale. This figure shows that the stress dependences of $\dot{\varepsilon}_{\text {min }}$ for all temperatures have the same trend. However, the slopes and therefore the values 
Table 1: Creep results for both alloys G and G1.

\begin{tabular}{|c|c|c|c|c|c|c|c|}
\hline \multirow[b]{2}{*}{ temperature } & \multirow[b]{2}{*}{$\begin{array}{l}\text { applied } \\
\text { stress }\end{array}$} & \multicolumn{3}{|c|}{ alloy G } & \multicolumn{3}{|c|}{ alloy G1 } \\
\hline & & $\begin{array}{l}\text { minimum creep } \\
\text { rate }\end{array}$ & $\begin{array}{l}\text { time to } \\
\text { fracture }\end{array}$ & $\begin{array}{l}\text { fracture } \\
\text { elongation }\end{array}$ & $\begin{array}{l}\text { minimum } \\
\text { creep rate }\end{array}$ & $\begin{array}{l}\text { time to } \\
\text { fracture }\end{array}$ & $\begin{array}{l}\text { fracture } \\
\text { elongation }\end{array}$ \\
\hline $\begin{array}{c}\mathrm{T} \\
{\left[{ }^{\circ} \mathrm{C}\right]}\end{array}$ & $\begin{array}{c}\sigma \\
{[\mathrm{MPa}]}\end{array}$ & $\begin{array}{c}\dot{\varepsilon}_{m} \\
{\left[\mathrm{~s}^{-1}\right]}\end{array}$ & $\begin{array}{c}\mathrm{t}_{f} \\
{[\mathrm{~h}]}\end{array}$ & $\begin{array}{c}\epsilon_{f} \\
{[\%]}\end{array}$ & $\begin{array}{c}\dot{\varepsilon}_{m} \\
{\left[\mathrm{~s}^{-1}\right]}\end{array}$ & $\begin{array}{c}\mathrm{t}_{f} \\
{[\mathrm{~h}]}\end{array}$ & $\begin{array}{c}\epsilon_{f} \\
{[\%]}\end{array}$ \\
\hline \multirow[t]{11}{*}{800} & 300 & $2.5 \times 10^{-10}$ & 9131.1 & 4.1 & $9.2 \times 10^{-11}$ & 10103.7 & 5.3 \\
\hline & 400 & $1.4 \times 10^{-09}$ & 1655.3 & 2.9 & $1.1 \times 10^{-09}$ & 1097.7 & 1.7 \\
\hline & 400 & $1.6 \times 10^{-09}$ & 2053.41 & & & & \\
\hline & 450 & $4.7 \times 10^{-09}$ & 454.535 & & $4.0 \times 10^{-09}$ & 666.59 & 2.9 \\
\hline & 500 & $1.3 \times 10^{-08}$ & 129.79 & 2.6 & & & \\
\hline & 550 & $3.2 \times 10^{-08}$ & 104.4 & 2.9 & & & \\
\hline & 600 & $1.2 \times 10^{-07}$ & 16.44 & 3.2 & $8.2 \times 10^{-08}$ & 50.6 & 3.4 \\
\hline & 650 & $2.2 \times 10^{-07}$ & 15.092 & & & & \\
\hline & 700 & $7.8 \times 10^{-07}$ & 6.492 & & $1.5 \times 10^{-06}$ & 2.653 & 2.9 \\
\hline & 750 & $5.8 \times 10^{-06}$ & 0.847 & & & & \\
\hline & 750 & $5.8 \times 10^{-06}$ & 0.847 & & & & \\
\hline \multirow[t]{7}{*}{900} & 200 & $1.2 \times 10^{-09}$ & 1985.6 & 5.3 & & & \\
\hline & 250 & $5.5 \times 10^{-09}$ & 607.3 & 5.4 & $1.0 \times 10^{-08}$ & 377.3 & 4.3 \\
\hline & 300 & $2.1 \times 10^{-08}$ & 230.75 & 5.8 & $3.5 \times 10^{-08}$ & 162 & 5.5 \\
\hline & 400 & $2.2 \times 10^{-07}$ & 37.05 & 7.7 & $3.9 \times 10^{-07}$ & 24.8 & 9.0 \\
\hline & 450 & $1.2 \times 10^{-06}$ & 7.829 & 7.7 & $6.5 \times 10^{-07}$ & 15.2 & 7.9 \\
\hline & 500 & $2.6 \times 10^{-06}$ & 3.88 & 7.0 & $2.4 \times 10^{-06}$ & 4.228 & 7.5 \\
\hline & 550 & $5.5 \times 10^{-06}$ & 1.384 & 5.1 & $1.1 \times 10^{-05}$ & 0.934 & 7.0 \\
\hline \multirow[t]{7}{*}{950} & 150 & $1.8 \times 10^{-09}$ & 1013.9 & 6 & $3.2 \times 10^{-09}$ & 829.1 & 4.9 \\
\hline & 200 & $9.8 \times 10^{-09}$ & 233.8 & 6.3 & $1.7 \times 10^{-08}$ & 189 & 5.1 \\
\hline & 200 & & & & $2.0 \times 10^{-08}$ & 166.1 & 4.8 \\
\hline & 250 & $7.7 \times 10^{-08}$ & 69.8 & 5.5 & $8.9 \times 10^{-08}$ & 60.4 & 6.0 \\
\hline & 300 & $3.0 \times 10^{-07}$ & 20 & 8.5 & $4.2 \times 10^{-07}$ & 15.4 & 5.3 \\
\hline & 400 & $3.6 \times 10^{-06}$ & 2.569 & 7.8 & $5.9 \times 10^{-06}$ & 2.134 & 8.2 \\
\hline & 450 & $1.6 \times 10^{-05}$ & 0.648 & 6.4 & $1.4 \times 10^{-05}$ & 0.953 & 9.6 \\
\hline \multirow[t]{6}{*}{1000} & 100 & $1.7 \times 10^{-09}$ & 1033.3 & 5.2 & $1.3 \times 10^{-09}$ & 931.3 & 1.8 \\
\hline & 100 & & & & $2.8 \times 10^{-09}$ & 969.7 & 4.7 \\
\hline & 150 & $3.6 \times 10^{-08}$ & 61.97 & 1.6 & $3.2 \times 10^{-08}$ & 94.3 & 5.1 \\
\hline & 200 & $2.6 \times 10^{-07}$ & 19.29 & 5.7 & $2.8 \times 10^{-07}$ & 18.8 & 8.7 \\
\hline & 250 & $1.5 \times 10^{-06}$ & 5.04 & 7.3 & $1.6 \times 10^{-06}$ & 4.6 & 7.3 \\
\hline & 300 & $1.3 \times 10^{-05}$ & 0.66 & 6.7 & $7.3 \times 10^{-06}$ & 1.33 & 9.1 \\
\hline
\end{tabular}

of the apparent stress exponent of the creep rate $n$ (Eq. (1)) for individual temperatures are slightly different. The exponent $n$ can be written as follows [13].

$$
n=\left(\frac{\partial \ln \dot{\varepsilon}_{\min }}{\partial \ln \sigma}\right)_{T} .
$$

The decrease in $n$ at the lower stresses indicates changes in the rate-controlling creep deformation mechanism(s) and/or microstructural instability. The determined values of $n$ (Table 2) correspond to the power-law dislocation creep regime [12-14]. Figure $9 \mathrm{~b}$ shows the variation of the time to fracture $t_{f}$ with the applied stress. It is clear from this plot that values of stress exponent $m$ of creep life (see Eq. (2)) are very similar to the values for the stress exponent $n$ indicating that both the creep deformation and fracture could be controlled by the same mechanism(s) [12]:

$$
t_{f} \approx B \cdot \sigma^{-m}, \quad \text { where } m=-\left(\frac{\partial \ln t_{f}}{\partial \ln \sigma}\right)_{T} .
$$

The values of exponents $n$ and $m$ are presented in Table 2 . With respect to non-linear curves in bilogarithmic plots the 
Table 2: Values of the stress exponent of the creep rate $n$ and the stress exponent of the creep life $m$ for superalloy MAR-247 of G variant for different testing temperatures within the used intervals of applied stress.

\begin{tabular}{ccccccccc}
\hline superalloy & \multicolumn{4}{c}{ parameter $\boldsymbol{n}$} & \multicolumn{5}{c}{ parameter $\boldsymbol{m}$} \\
\cline { 2 - 9 } & $800^{\circ} \mathrm{C}$ & $900^{\circ} \mathrm{C}$ & $950^{\circ} \mathrm{C}$ & $1000^{\circ} \mathrm{C}$ & $800^{\circ} \mathrm{C}$ & $900^{\circ} \mathrm{C}$ & $950^{\circ} \mathrm{C}$ & $1000^{\circ} \mathrm{C}$ \\
\hline MAR-M247 & $6-14$ & $5-14$ & $4-13$ & 8 & $6-15$ & $4-11$ & $4-11$ & 6 \\
\hline
\end{tabular}
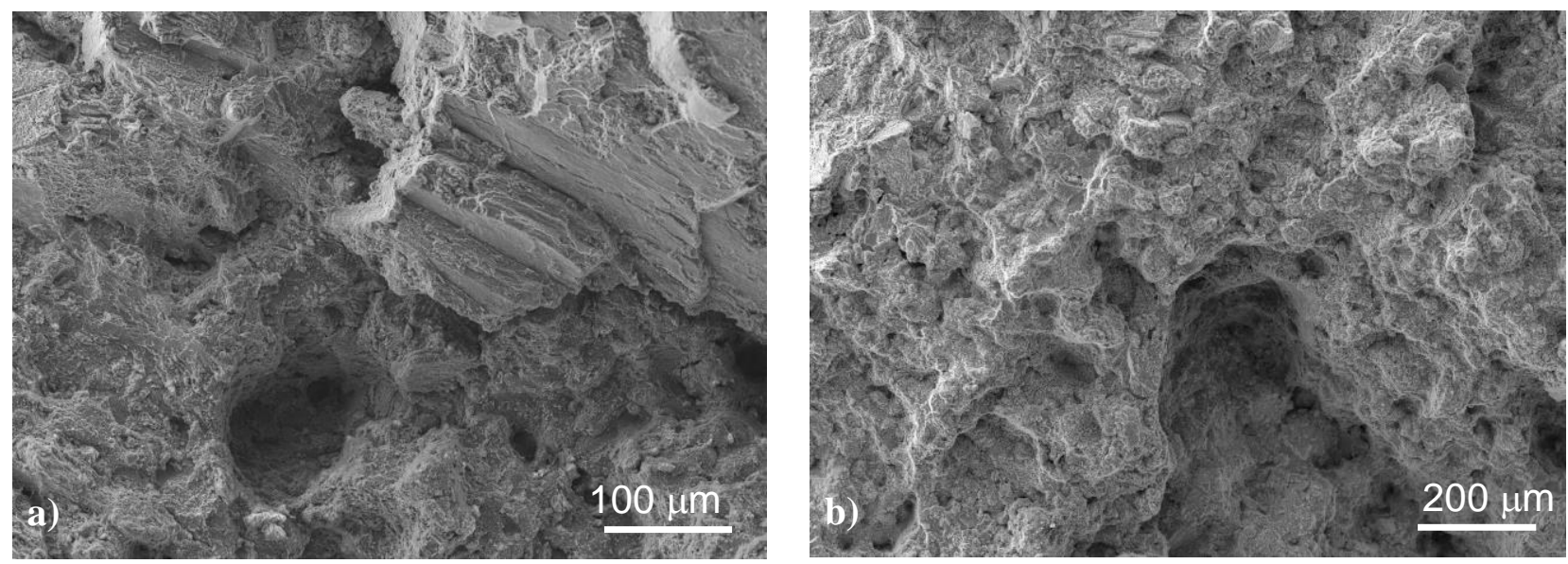

Figure 7: Fracture surfaces of creep specimen of superalloy MAR-M247 (G variant) loaded by stress $400 \mathrm{MPa}$ at temperatures a) $800^{\circ} \mathrm{C}$ and b) $950^{\circ} \mathrm{C}$.
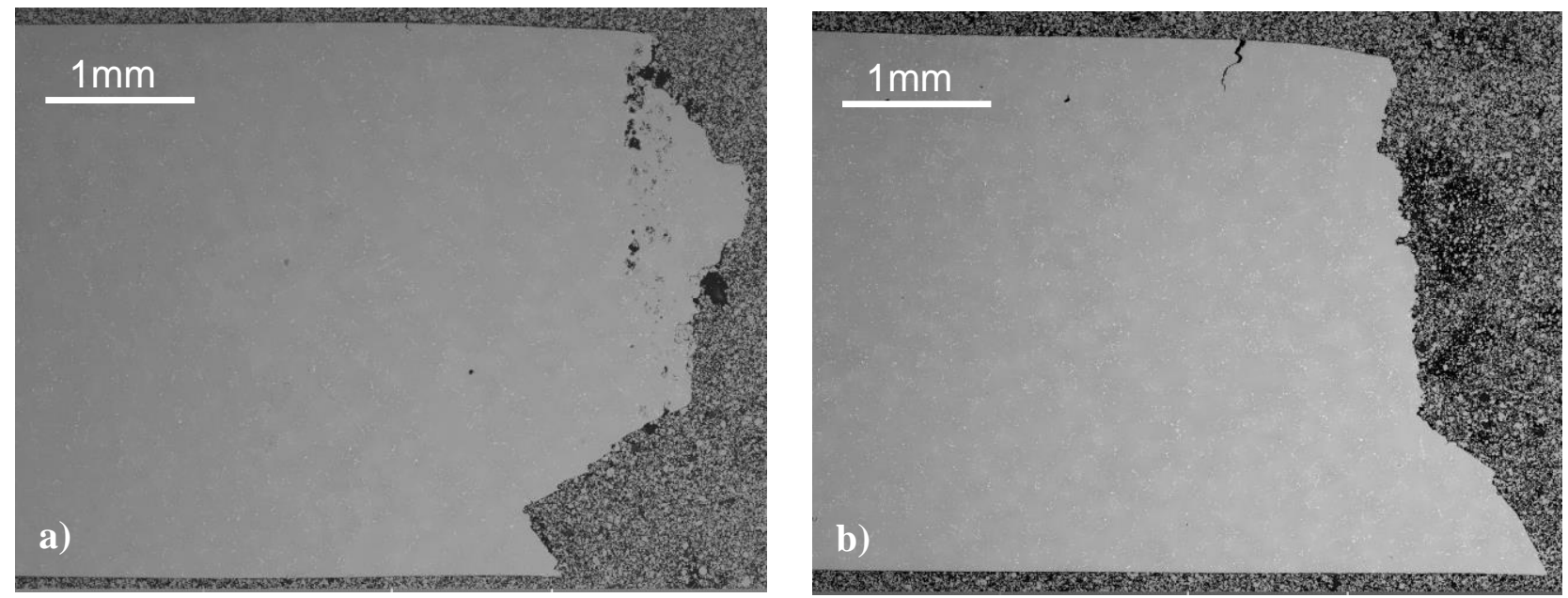

Figure 8: Fracture longitudinal cross-sections of creep specimen of superalloy MAR-M247 (G variant) loaded by stress 400 MPa at temperatures a) $800^{\circ} \mathrm{C}$ and b) $950^{\circ} \mathrm{C}$.

values of $n$ and $m$ were determined as local slopes of the relevant part of creep curves.

The values of the minimum creep rate and the time to fracture for the alloy G1 were nearly the same for the corresponding loading conditions (Figures 10a, b and Table 1). Thus, it is reasonable to perform the following analysis of the creep deformation behaviour only from data corresponding to the $\mathrm{G}$ alloy.
The results for creep plastic deformation of superalloy specimens are presented in Figure 11. The creep testing revealed very low values of creep plasticity characterized by values of the fracture elongations. However, while fracture elongation was about $3 \%$ at $800^{\circ} \mathrm{C}$, increasing the testing temperature slightly increased the creep ductility to about 5 to $8 \%$. The increasing creep plasticity (elongation) of superalloy MAR-M247 may be explained by the course of its 


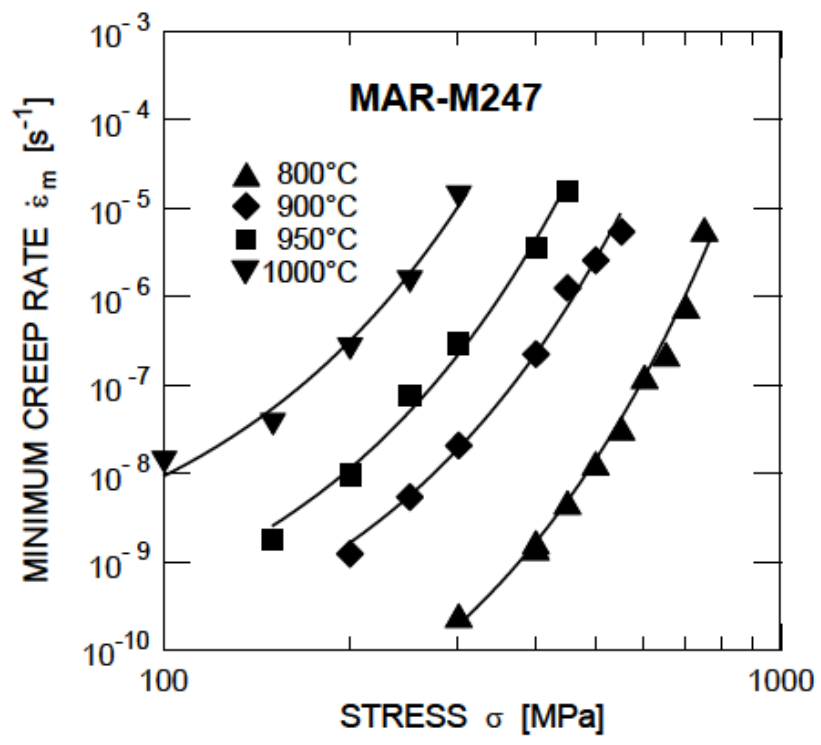

(a)

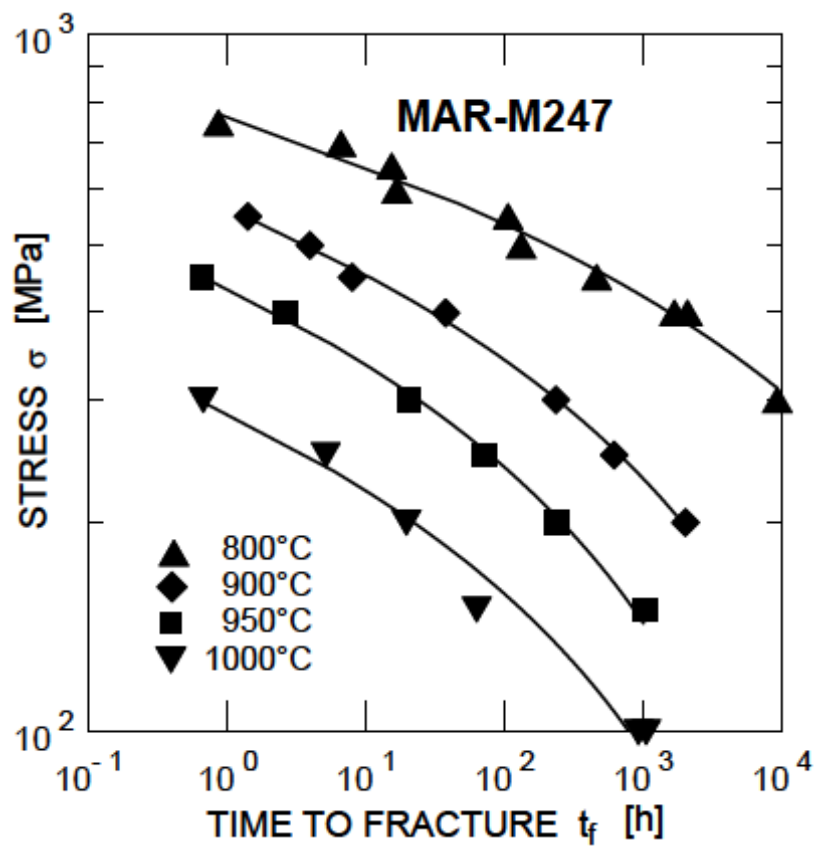

(b)

Figure 9: Stress dependences of a) minimum creep rate, and b) time to fracture for superalloys MAR-M247 (variant G).

tertiary creep behaviour (Figure 1) and/or creep fracture type.

The minimum creep rates for each test were determined during very early stage of deformation, where the value of creep deformation is rather small. The apparent activation energy of creep $\Delta Q_{c}$ can be obtained from the creep test with constant loading according to the Dorn's

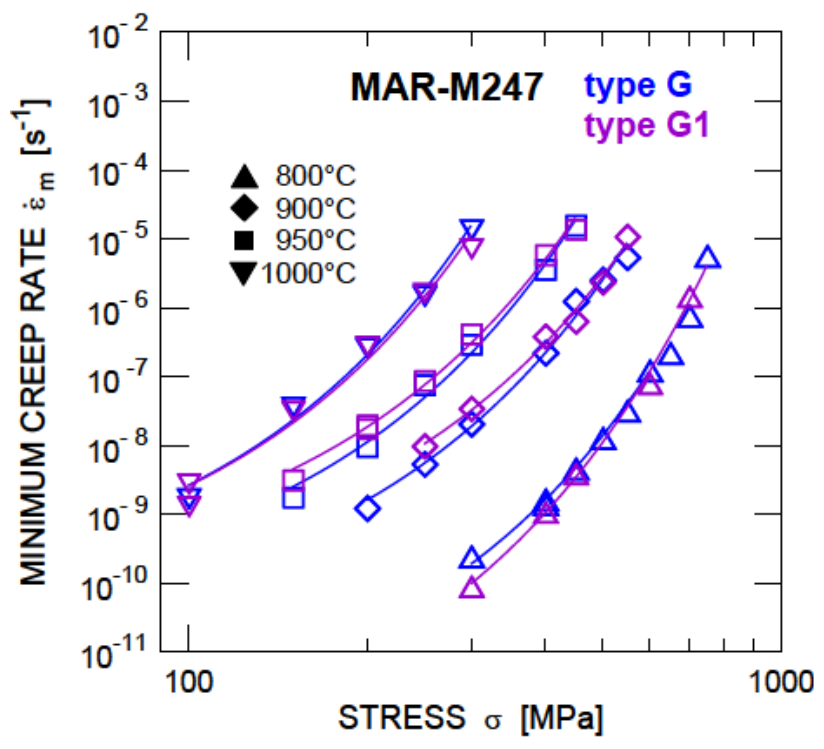

(a)

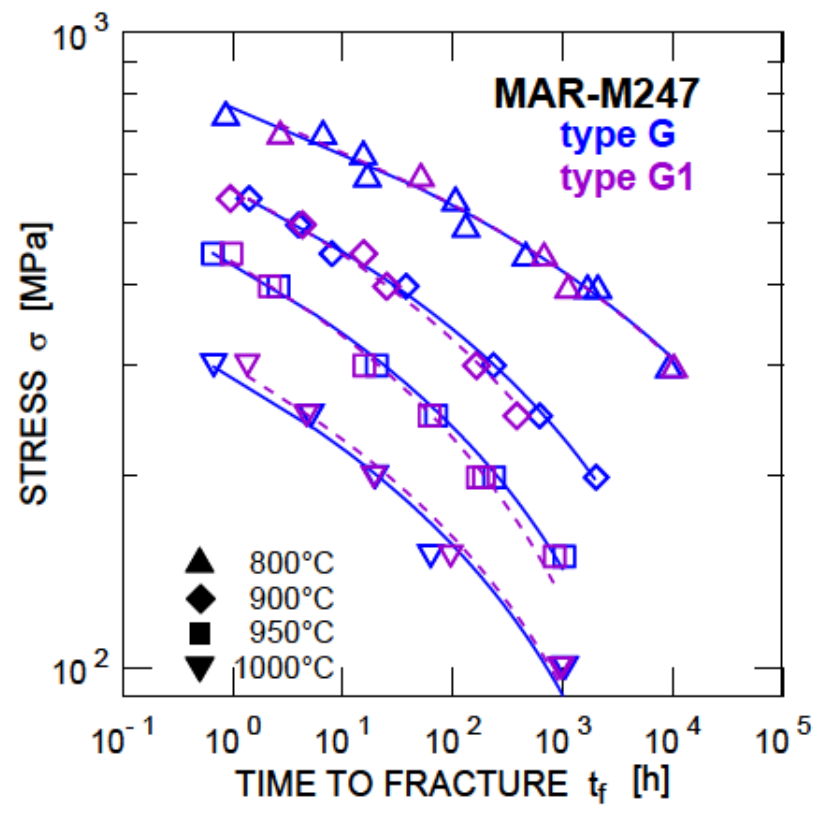

(b)

Figure 10: Comparison of the stress dependence of a) minimum creep rate, and b) time to fracture for superalloys MAR-M247 of G variant (solid line) and of $\mathrm{G} 1$ variant (dashed line).

relationship

$$
\dot{\varepsilon}_{\min }=A \sigma^{n} \exp \left(-\frac{\Delta Q_{c}}{R T}\right)
$$

where $A$ is a constant, $R$ is the gas constant and $T$ is temperature. So that

$$
\Delta Q_{c}=-\left(\frac{\partial \ln \dot{\varepsilon}_{\text {min }}}{\partial(1 / R T)}\right)_{\sigma}
$$




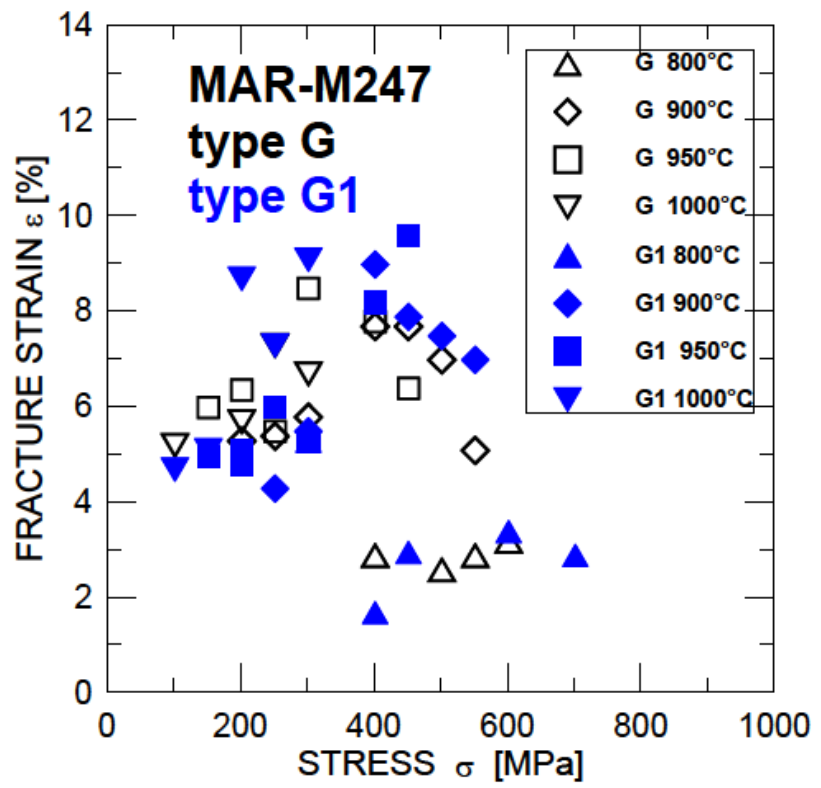

Figure 11: Stress dependence of fracture strain for superalloy MAR-M247 G and G1 alloys at different temperatures and applied stresses.

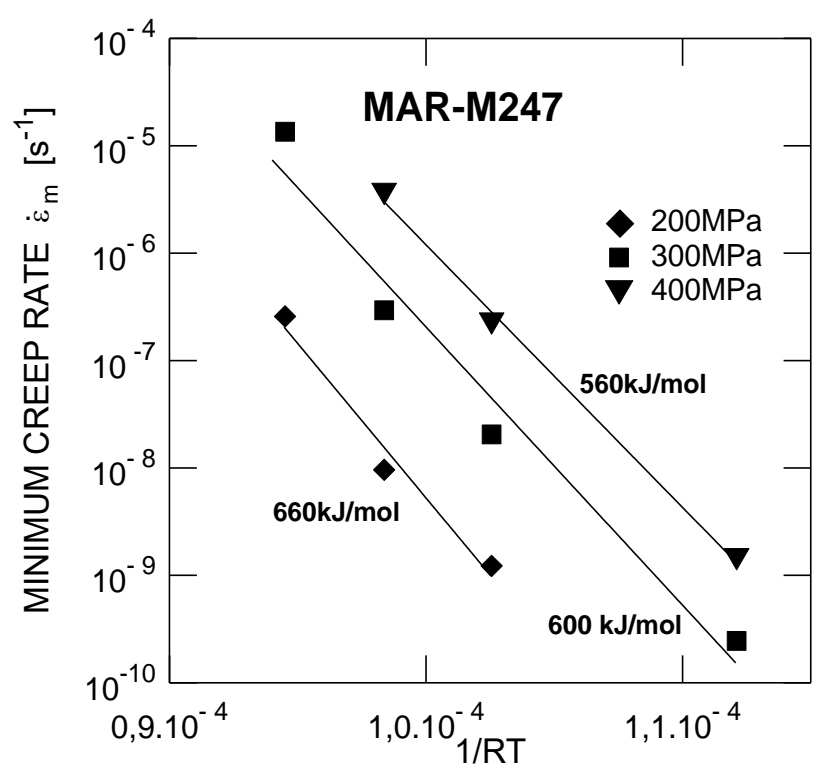

Figure 12: Determination of the activation energy of creep of the MAR-M247 alloy at different levels of applied stress.

The results of an activation analysis are presented in Figure 12.

Experimentally obtained values of the apparent activation energy of creep for MAR-M247 (560-660 kJ/mol) are much higher in comparison with the energy of volume self-diffusion of the Ni species $(284 \mathrm{~kJ} / \mathrm{mol})$ [15]. Nevertheless, the precipitation-strengthened alloys typically exhibit such high and temperature-dependent values of the

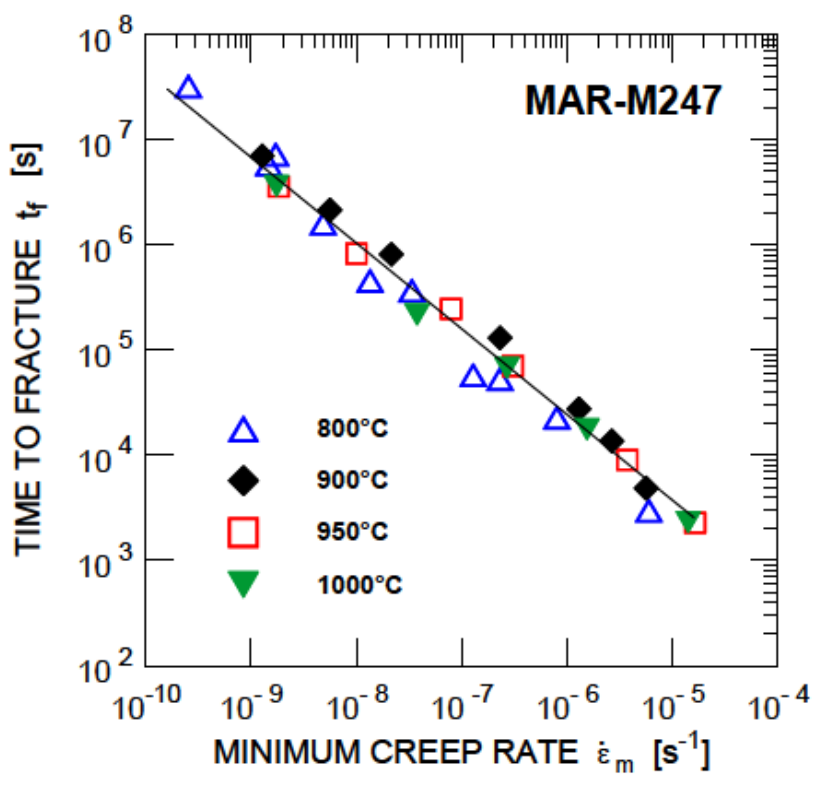

Figure 13: Monkman-Grant relationship for different temperatures for the G alloy.

apparent creep activation energy [13], which corresponds to a model of diffusion-controlled dislocation movement by glide and climb. Moreover, the increased value of the apparent creep activation energy can be explained by a presence of back stress induced by precipitated particles [13, $16,17]$.

The other important field of interest about nickelbased superalloy MAR-M247 (especially for its use in industry) is the life assessment i.e. prediction of the lifetime. There are several empirical formulas that, on different levels of sophistication, describe the dependence of the creep life on stress and on temperature. One such relationship proposed by Monkman and Grant [18] seems to have wider applicability than might be reasonably expected. The Monkman-Grant relationship

$$
t_{f}=\left(C / \dot{\varepsilon}_{\min }\right)^{\alpha},
$$

where $C$ and $\alpha$ are constants, has frequently been used for the prediction of creep life of creep-resistant materials.

It was found (Figure 13) that the experimental data obey the Monkman-Grant relationship with surprising accuracy, as exhibited by the nearly identical values of the constant $\alpha$ for different temperatures ( $\alpha=0.83$ for $800^{\circ} \mathrm{C}$ and $\alpha=0.85$ for $950^{\circ} \mathrm{C}$ ).

The Monkman-Grant relationship can be modified [19] for the creep data in terms of normalized creep fracture strains $\varepsilon_{f} / t_{f}$ and the minimum creep rates $\dot{\varepsilon}_{\text {min }}$ as shown in Figure 14. Nearly all experimental points fall on one master solid line. The double logarithmic plot in Figure 14 indicates that the experimental data can be represented by 


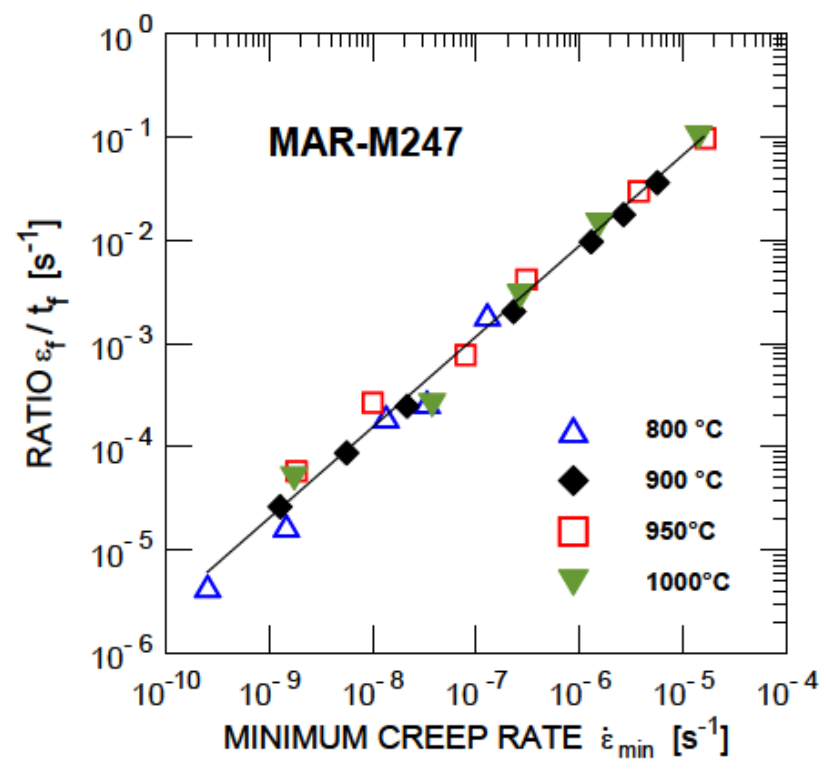

Figure 14: Normalized Monkman-Grant relationship for different temperatures for the $\mathrm{G}$ alloy.

a line with exponent $a \cong 1.0$. This suggests that fracture process is controlled by a dislocation mechanism as similar to that in creep deformation.

In summary, based on the results of creep testing of two grain-sized variants of the nickel-based MAR-M247 superalloy, the difference in the creep behaviour of variants $\mathrm{G}$ and $\mathrm{G} 1$ is nearly negligible. It was suggested that under creep testing conditions used in this study, the creep behaviour of the alloys corresponds to power-law or dislocation creep. It should be noted that no proposed formula for the minimum creep rate (e.g. Eq. 3) in the region of dislocation creep complied with explicit dependence on grain size $[13,14,20]$. Furthermore, creep deformation in this class of superalloys occurs predominantly in the matrix phase. One possible deformation mechanism is grain boundary sliding, which could be minimized by a coarser grain size [13]. However, creep in superalloys is very dependent on a number of microstructural parameters. Those of primary importance are the $\gamma^{\prime}$ precipitate volume fraction, lattice mismatch and morphology. It was reported [21] that creep life roughly linearly increases with the $\gamma^{\prime}$ volume fraction. The lattice mismatch between the matrix and $\gamma^{\prime}$ also influences the creep strength [22, 23]. For the best creep strength, the $\gamma^{\prime}$ particles should be very small, but this may cause undesirable losses in ductility. Coarse primary $\gamma^{\prime}$ phase particles with an average size of $\sim 2 \mu \mathrm{m}$ were observed (see Section 3.2.) in both variants G and G1. These large particles could be caused by the microsegregation of alloying elements during the solidification process and were difficult to refine or even dissolve during heat treatment. Carbides play an important role in the creep strengthening mainly by pinning the grain boundaries and subsequently prevent the grain boundaries from sliding and migrating.

\section{Conclusions}

The creep behaviour of two variants of cast nickel-based MAR-M247 superalloy with different grain sizes $5 \mathrm{~mm}$ (variant $\mathrm{G}$ ) and $2 \mathrm{~mm}$ (variant $\mathrm{G} 1$ ) was studied at testing temperatures $800,900,950$ and $1000^{\circ} \mathrm{C}$ and in the wide range of applied stresses ranging from 150 to $700 \mathrm{MPa}$. The main results are as follows:

- The values of the minimum creep rate and the time to fracture for both variants under the same loading condition are nearly identical. The grain sizes of $G$ and G1 are too large to make a difference in hindering dislocation slip, which was found to be the main deformation mechanism.

- The determined varying values of the stress exponent of creep rate $n$ indicated that creep tests were carried out in power-law dislocation regime. The decrease of exponent $n$ at lower stresses may be indicative of some changes in the rate-controlling creep deformation mechanism and/or microstructural instability. The determined values of the stress exponents $n$ and $m$ are very similar, which indicate an activity of the same controlling mechanism for creep deformation and fracture.

- Creep fracture strain for both superalloy variants is about $3 \%$ at $800^{\circ} \mathrm{C}$. Increasing the testing temperature slightly increases ductility to an interval within 5 to $8 \%$. The changes in creep plasticity of both alloys could be explained by the instability of the microstructure and changing of the creep fracture mode (size changes of $\gamma^{\prime}$ phase and the $\mathrm{M}_{6} \mathrm{C}$ and/or $\mathrm{M}_{23} \mathrm{C}_{6}$ carbide types over the time including their coarsening and/or dissolution).

- The microstructure of superalloys MAR-M247 of both variants $\mathrm{G}$ and $\mathrm{G} 1$ consists of a $\gamma$ matrix with eutectic, $\gamma^{\prime}$ strengthening cubic precipitates, and $\mathrm{M}_{6} \mathrm{C}$ and/or $\mathrm{M}_{23} \mathrm{C}_{6}$ carbides. Increasing the temperature induces the dissolution of some carbides. It can be explained by relative instability of $\mathrm{M}_{23} \mathrm{C}_{6}$ type carbides compared to $\mathrm{M}_{6} \mathrm{C}$ at elevated temperatures.

- Fracture surfaces for the G and G1 variants exhibit a more ductile character at higher temperatures, while at lower temperature, a mixture of brittle and ductile fracture mode was observed. 
Acknowledgement: This research conducted in cooperation with PBS VB, a.s., was supported by the project CZ.01.1.02/0.0/0.0/15 019/0002421 of the Ministry of Industry and Trade of the Czech Republic, and by the Ministry of Education, Youth and Sports of the Czech Republic under the project m-IPMinfra (CZ.02.1.01/0.0/0.0/16_013/0001823).

\section{References}

[1] M.V. Nathal, R.D. Maier and L.J.Ebert, Metall. Trans. A 13 (1982) 1767-1774.

[2] M.V. Nathal, R.D. Maier and L.J.Ebert, Metall. Trans. A 13 (1982) 1775-1783.

[3] J.E.Doherty, B.H. Kear and A.F.Giamei, J.Miner Met. Mat.Soc. 23 (11) (1971) 59-62.

[4] D.N.Duhl and C.P. Sullivan, J.Miner Met. Mat.Soc. 23 (7) (1971) 38-40.

[5] D.A. Chang, R. Nasser-Rafi and S.L. Robertson, Mechanical properties of controlled grain structure (CGS) alloy 718, edited by E.A. Loria, Superalloy 718,625 and various derivatives, The Mineralogical Society, Pensylvania, 1991, pp. 271-286.

[6] J.H. Liao, H.Y. Bor, C.N. Wei, C.G. Chao and T.F. Liu, Mater. Sci. Eng. A 539 (2012) 93-100.doi:10.1016/j.msea.2012.01.059.

[7] C.T. Sims, N.S. Stoloff and W.C. Hagel, Superalloys II, John Wiley \& Sons, New York (1987), 255-256.

[8] S.Liu, Ch.Liu, L.Ge, X. Zhang, T. Yu, P.Yan and Ch. Wang, Scripta Mat. 138 (2017) 100-104. doi:10.1016/j.scriptamat.2017.05.036
[9] J. Chen, J.H. Lee, C.Y. Jo, S.J. Choe and Y.T. Lee, Mater. Sci. Eng. A 247 (1988) 113-125. doi: 10.1016/S0921-5093(97)00761-2

[10] Y.L. Tsai, S.F. Wang, H.Y. Bor and Y.F. Hsu, Mat. Sci.Eng. A 571, (2013) 155-160. doi:10.1016/j.msea.2013.02.002

[11] L.R. Liu, T. Jin, N.R. Zhao, X.F. Sun, H.R. Guan, Z.Q. Hu, Mat. Sci. Eng A 361 (2003) 191-197. doi:10.1016/S0921-5093(03)00517-3

[12] A.J. Kennedy, Processes of Creep and Fatigue in Metals, Oliver and Boyd, McMillan, Edinburgh, 1962.

[13] J. Cadek, Creep in Metallic Materials, Elsevier Science Publishers, Amsterdam, Netherlands, 1988.

[14] F. Garofalo, Fundamentals of Creep and Creep-Rupture in Metals, New York,1965.

[15] M.F. Ashby, H.J. Frost, Deformation-Mechanism Maps, The Plasticity and Creep of Metals and Ceramics, Oxford, New York, 1982.

[16] O.D.Sherby and J.Weertman, Acta Metall. 27 (1979), 387-400.

[17] A.C. Picasso and A.J. Marzocca, Scripta Mater. 41 (1999) 797-802. doi:10.1016/S1359-6462(99)00229-8

[18] F.C. Monkman and N.J. Grant, Proc. ASTM Vol. 56 (1956), p.593.

[19] V. Sklenička, K. Kuchařová, P. Král, M. Kvapilová and J. Dvořák, Kovove Mater. 55 (2017) 69-80. doi: 10.4149/km_2017_2_69

[20] M.E. Kassner, Fundamentals of Creep in Metals and Alloys, second.ed., Elsevier Ltd., Amsterdam, 2009.

[21] S. Floreen, Mechanical behavior, edited by C.T. Sims, N.S. Stoloff, W.C. Hagel Superalloys II, John Wiley \& Sons, New York, 1987, pp. 241-262.

[22] F. Schubert, Superalloys Source Book, ASM, Metals Park, USA, 1984.

[23] J. Coakley, E.A. Lass, D. Ma, M. Frost, H.J. Stone, D.N. Seidman and D.C. Dunand, Acta Mater. 136 (2017) 118-125. doi:org/10.1016/j.actamat.2017.06.025 